\title{
Use of Apple Pomace as Substrate for Production of Lactiplantibacillus plantarum Malolactic Starter Cultures
}

\author{
Victoria Cerdeira ${ }^{1}$, Natalia S. Brizuela ${ }^{2}{ }^{\circledR}$, Sebastián M. E. Bravo ${ }^{3}$, Bárbara M. Bravo-Ferrada ${ }^{2} \oplus$, \\ Danay Valdés La Hens ${ }^{2}$, Adriana C. Caballero ${ }^{3}$, Liliana C. Semorile ${ }^{2} \mathbb{D}$ and E. Elizabeth Tymczyszyn ${ }^{2, *} \mathbb{D}$ \\ 1 CERMO-FC Research Center, Department of Biological Sciences, Université du Québec à Montréal (UQAM), \\ 141 Av. du Président-Kennedy, Montréal, QC H2X 3X8, Canada; vicky_cerdeira@hotmail.com \\ 2 Laboratorio de Microbiología Molecular, Instituto de Microbiología Básica y Aplicada (IMBA), Departamento \\ de Ciencia y Tecnología, Universidad Nacional de Quilmes, Roque Sáenz Peña $N^{\circ}$ 352, Bernal, \\ Buenos Aires B1876BXD, Argentina; nsbrizuela@gmail.com (N.S.B.); \\ barbaramercedes@hotmail.com (B.M.B.-F.); dvhens@unq.edu.ar (D.V.L.H.); lsemorile@unq.edu.ar (L.C.S.) \\ 3 Facultad de Ciencias y Tecnología de Alimentos, Instituto de Investigación y Desarrollo en Ingeniería de \\ Procesos, Biotecnología y Energías Alternativas (PROBIEN), Universidad Nacional del Comahue, CONICET, \\ Buenos Aires 1400, Argentina; sebastian.bravo@facta.uncoma.edu.ar (S.M.E.B.); \\ adriana.caballero@facta.uncoma.edu.ar (A.C.C.) \\ * Correspondence: elitym@yahoo.com.ar; Tel./Fax: +54-11-4365-7100 (ext. 5636)
}

check for updates

Citation: Cerdeira, V.; Brizuela, N.S.; Bravo, S.M.E.; Bravo-Ferrada, B.M.; Valdés La Hens, D.; Caballero, A.C.; Semorile, L.C.; Tymczyszyn, E.E. Use of Apple Pomace as Substrate for Production of Lactiplantibacillus plantarum Malolactic Starter Cultures. Fermentation 2021, 7, 244. https:// doi.org/10.3390/fermentation7040244

Academic Editor: Diomi Mamma

Received: 13 September 2021

Accepted: 9 October 2021

Published: 29 October 2021

Publisher's Note: MDPI stays neutral with regard to jurisdictional claims in published maps and institutional affiliations.

Copyright: (c) 2021 by the authors. Licensee MDPI, Basel, Switzerland. This article is an open access article distributed under the terms and conditions of the Creative Commons Attribution (CC BY) license (https:// creativecommons.org/licenses/by/ $4.0 /)$.

\begin{abstract}
The by-products of the food industry are an economic alternative as a source of nutrients to obtain biomass. At the same time, theiruse could solve the environmental problem related to their disposal, which is highly polluting due to their elevated biochemical oxygen demand. In this work, we seek to optimize the production of cellular biomass of two native Patagonian strains of Lactiplantibacillus plantarum (UNQLp 11 and UNQLp155), selected for its oenological and technological properties, using apple pomace (AP), a residue from the juice and cider industry. The supplementation of AP with yeast extract, salts, and Tween 80 (SAP), proved to maintain the growth of the Lpb. plantarum strains, similar to the commercial medium used to grow LAB (De Man, Rogosa, Sharpe, MRS). Cultures grown in sAP medium showed good tolerance to wine conditions (high ethanol content and low $\mathrm{pH}$ ), demonstrated by its ability to consume L-malic acid. The subsequent inoculation of these cultures in sterile wines (Merlot and Pinot noir) was carried out at laboratory scale, evaluating cell viability and L-malic acid consumption for 21 days at $21^{\circ} \mathrm{C}$. Cultures grown in sAP media showed a similar performance to MRS media. Thus, sAP media proved to be a suitable substrate to grow oenological Lpb. plantarum strains where cultures (with high size inoculums) were able to drive malolactic fermentation, with an L-malic acid consumption higher than $90 \%$.
\end{abstract}

Keywords: lactic-acid bacteria; sustainable; wine; malolactic fermentation; food by-products

\section{Introduction}

Lactiplantibacillus plantarum strains are one of the most important lactic-acid bacteria (LAB) able to drive malolactic fermentation (MLF) during the winemaking process. First, yeasts perform alcoholic fermentation (AF) transforming the must into wine. During or after the AF, MLF can occur, consisting on the decarboxylation of L-malic acid, which reduces acidity of wine and contributes to microbial stability (by reducing carbon sources that can be used by deleterious microorganisms) [1-5]. Additionally, LAB enzymatic activities improve the aromatic profile of the wine [6-9]. MLF can occur spontaneously by the action of native LAB from the grape and the cellar, but wine stress factors (ethanol, low $\mathrm{pH}$, sulfite, etc.) can reduce the bacterial viability. This can lead to undesirable results, such as an increase in volatile acidity, the consumption of residual sugars and the formation of unwanted metabolites such as biogenic amines. To control the process, malolactic starter cultures can be added during winemaking, in order to guarantee the success of MLF [10]. 
The use of starter cultures formulated with indigenous LAB strains from a productive region is an expanding practice in viticulture. This allows the maintenance of the typicity of the terroir and possesses strains better adapted to the agroecological characteristics of the cultivars. Instead, commercial starters are formulated with LAB strains isolated from regions different to those in which they are going to be used [11-16].

For this purpose, two strains of Lpb. plantarum (UNQLp 11 and UNQLp 155) were obtained from Patagonian Pinot noir wines (in spontaneous MLF stage) and selected according to their oenological and technological characteristics. Their ability to survive to wine conditions, a good L-malic acid consumption, and the capacity to improve the aromatic profile, among others, reveals them as good candidates to be used as malolactic starter cultures for the Patagonian region [7,8,17-19]. Additionally, Lpb. plantarum cultures have several advantages over the main microorganism involved in the MLF process, Oenococcus oeni. Namely, Lpb. plantarum grows faster than O. oeni in various carbon sources [20]. Additionally, we demonstrated in previous work, that some strains can be inoculated in wine without previous acclimation (treatment to pre-adapt cells to wine stress by incubation in a rich medium at sub-lethal stress conditions) [21], reducing costs and time in obtaining biomass [18].

The production of large-scale starter cultures requires analyzing the conditions to obtain cellular biomass at low cost, and in a sustainable way [22]. Apple pomace (AP), also named apple bagasse, is one of the main agro-industrial by-products of the Patagonian region (from juice and cider elaboration). Its use to obtain biomass could solve environmental problems related to its treatment and disposal, giving them an added value [23]. $\mathrm{AP}$ is rich in simple sugars such as glucose, fructose, and sucrose [23], making it an economic carbon source. This media has been previously used to obtain metabolic products of fermentation such as ethanol and lactic acid [24,25]. Recently AP has been optimized to produce oenological yeast biomass [23] but, to our knowledge, it has not yet been used to obtain LAB biomass for biotechnological purposes.

LABs are known as nutritionally fastidious microorganisms [26] thus, nutrient supplementation in growth media must be considered [20]. At the same time, the use of Lpb. plantarum strains as malolactic starter cultures require their survival to the stressful wine environment [21]. For these reasons, LABs are sometimes pre-adapted to these harsh conditions by exposure to sub-lethal stresses, such as incubation in an acclimation medium with a low ethanol concentration [21] or growing at low $\mathrm{pH}$ [27].

Therefore, the aim of this work was the biomass production of two native oenological Lpb. plantarum strains (UNQLp 11 and UNQLp 155) using AP as a base medium. For this purpose, the nutritional supplementation and the $\mathrm{pH}$ adjustment were analyzed. Subsequently, strains grown in the best performance media were inoculated in sterile wine samples (final stage of alcoholic fermentation) of Merlot and Pinot noir and incubated at laboratory scale. The posterior analysis of cell viability and L-malic acid consumption suggests their potential application as a low-cost medium, to produce native malolactic starter cultures of the Patagonian region.

\section{Materials and Methods}

\subsection{Bacterial Strains and Growth Conditions}

UNQLp 11 and UNQLp 155 Lpb. plantarum strains (Gene Bank Accession Number Complete Genome: CP031140 and 16S rRNA GenBank Accession Numbers: KC562904, respectively), were obtained from Pinot noir wine samples $[17,18]$, where MLF was spontaneous. Cultures were kept frozen at $-20{ }^{\circ} \mathrm{C}$ in MRS broth (De Man, Rogosa, Sharpe), with glycerol $(20 \% v / v$, as a stock culture). For fresh bacteria cultures, $1 \mathrm{~mL}$ of stock culture was grown in 10mL of MRS broth (Biokar Diagnostics, Beauvais, France) [28], at $28{ }^{\circ} \mathrm{C}$ and $\mathrm{pH} 6.5$ for $48 \mathrm{~h}$ in anaerobic conditions (stationary phase $\sim 9 \mathrm{LogCFU} / \mathrm{mL}$ ). 


\subsection{Selection of Nutritional Supplementation}

Apple pomace (AP) by-product was obtained from the production of natural juices squeezed from apples, free of additives (kindly donated by "Jugos Villa Regina ${ }^{\circledR}$ ", Province of Río Negro, Argentina). The physicochemical and microbial characterization of AP was previously reported by Bravo et al., 2019 [23]. AP was used at 50\% w/w in distilled water and sterilized in an autoclave at $120^{\circ} \mathrm{C}$ for $15 \mathrm{~min}$. Then, AP medium was centrifuged at $5000 \times g$ for $20 \mathrm{~min}$ and the clarified supernatant was used as base medium. Lpb. plantarum strains were inoculated at $1 \% v / v(0.1 \mathrm{~mL}$ of culture in stationary phase in $10 \mathrm{~mL}$ of fresh medium) in AP, AP supplemented with yeast extract $1 \% w / v$ (yeAP) and AP supplemented with yeast extract $1 \% w / v$, Tween $801 \mathrm{~mL} / \mathrm{L}$ and salts (ammonium citrate $2 \mathrm{~g} / \mathrm{L}, \mathrm{K}_{2} \mathrm{HPO}_{4}$ $2 \mathrm{~g} / \mathrm{L}, \mathrm{MgSO}_{4}$ 0,1 g/L and $\mathrm{MnSO}_{4}$ 0,05 g/L)(sAP) according to Cerdeira et al., 2019 [20]. Additionally, $\mathrm{pH}$ was adjusted at: 3.6, 4.5 and $6.2( \pm 0.1)$ (by adding $\mathrm{NaOH}$ or $\mathrm{HCl} 6 \mathrm{M})$, to evaluate the pre-exposure to sub-lethal stress factors [27]. MRS broths, at $\mathrm{pH} 3.6$ and 6.2, were used as control medium (highest and lowest acidity values). For each growth condition the optical density (OD) at $600 \mathrm{~nm}$ was measured in a microplate reader (Biotek, Cytation 3), at $28^{\circ} \mathrm{C}$, for 5 days. At stationary phase, cell viability samples were evaluated by plate count on MRS agar.

\subsection{Synthetic Wine Incubation}

Stationary phase cultures $(\sim 1 \mathrm{~mL})$, obtained from each growth condition (sAP at different $\mathrm{pH}$ ) were centrifuged and inoculated in an equal volume of synthetic wine $(5 \mathrm{~g} / \mathrm{L}$ tartaric acid, $4.5 \mathrm{~g} / \mathrm{L} \mathrm{L}$-malic acid, $0.6 \mathrm{~g} / \mathrm{L}$ acetic acid, $2 \mathrm{~g} / \mathrm{L}$ fructose, $2 \mathrm{~g} / \mathrm{L}$ glucose, $13 \%$ $v / v$ ethanol and $\mathrm{pH} 3.5 \pm 0.2$ ). They were then incubated for 7 days at $21^{\circ} \mathrm{C}$. Samples were taken on day 7 to determine cell viability and L-malic acid consumption. As control, MRS broth cultures at pH 3.6 and 6.2 (highest and lowest acidity values), were also evaluated.

\subsection{Fermentation Assays at Laboratory Scale in Sterile Pinot Noir and Merlot Wines}

Cultures from the best growth condition (defined by the performance in synthetic wine incubation) were inoculated in $10 \mathrm{~mL}$ of Pinot noir $(14.3 \% v / v$ ethanol, L-malic acid $2.3 \mathrm{~g} / \mathrm{L}, \mathrm{pH}$ 3.7) and Merlot (12.2\% v/v ethanol, L-malic acid 2.1 g/L, pH 3.45) wines (both at the end of AF). These wines were previously sterilized by filtration through $0.2 \mu \mathrm{m}$ pore size (Sartorius Stedim Biotech GmbH, Göttingen, Germany) and inoculated at two different bacterial concentrations, $\sim 7$ and $\sim 8$ LogCFU/mL (cultures from MRS or sAP, without acclimation treatment). The wine samples were incubated for 21 days at $21^{\circ} \mathrm{C}$, taking samples at 0 and $24 \mathrm{~h}$, and at 7,14, and 21 days, to determine cell viability and L-malic acid consumption. As control, similar sterile wine samples were inoculated with Lpb. plantarum cultures grown in MRS broth $\mathrm{pH}$ 6.3.

\subsection{Cell Survival}

Cell viability was determined by bacterial colony count on MRS agar plates, incubated at $28{ }^{\circ} \mathrm{C}$ for $72 \mathrm{~h}$. Serial dilutions $(1 / 10)$ with $0.9 \%$ physiological solution were done, and $0.1 \mathrm{~mL}$ of each dilution was plated on MRS agar. The plates were incubated at $28^{\circ} \mathrm{C}$ for $72 \mathrm{~h}$, in aerobiosis, and the results were expressed in CFU $/ \mathrm{mL}$.

\subsection{L-Malic Acid Consumption}

The concentration in $\mathrm{g} / \mathrm{L}$ of the remaining L-malic acid was evaluated by the L-Malic Acid Enzymatic Kit (BioSystems SA, Barcelona, Spain).

The percentage of L-malic acid consumed (\%MAC) after 21 days of incubation was calculated following the Equation (1):

$$
\% M A C=100-\left(\left[M A_{f}\right] 100 /\left[M A_{0}\right]\right)
$$

where $\left[M A_{0}\right]$ is the initial concentration of $\mathrm{L}-$ malic acid in the wine used and $\left[M A_{f}\right]$ is the final concentration measured in the wine after 21 days of incubation. 
At the same time, an exponential one-phase decay equation model was used for fitting the performed $M A C$ kinetic by the different strains tested in sterile wine. The Equation (2) for this model was obtained by the GraphPad Prism ${ }^{\circledR}$ software and it is:

$$
\left[M A_{t}\right]=\left(\left[M A_{0}\right]-\left[M A_{i}\right]\right) e^{-K t}+\left[M A_{i}\right]
$$

where $\left[M A_{t}\right]$ is the $\mathrm{L}$-malic acid concentration at time $=\mathrm{t},\left[M A_{0}\right]$ is the initial concentration of L-malic acid, $\left[M A_{i}\right]$ is the L-malic acid concentration at infinite time and $K$ is the rate constant.

\subsection{Statistical Analysis}

All of the assays were performed on triplicate using independent batch cultures. The statistical analysis was carried out with the GraphPad Prism version $6.01{ }^{\circledR}$ program, using ANOVA (Analysis of Variance). The results were expressed with the mean \pm their standard deviation and the differences were considered significant when $p<0.05$.

\section{Results}

\subsection{Growth Kinetics in AP and sAP}

$\mathrm{AP}$ and sAP media were studied for biomass production of two $L p b$. plantarum strains, compared to classical growth in MRS broth. Figure 1 shows the growth kinetics of UNQLp 11 and UNQLp 155 strains in AP, yeAP, and sAP media, in comparison with the commercial MRS broth, at different $\mathrm{pH}$. The effect of nutrient supplementation was dramatic for both strains. The addition of yeast extract 1\% w/v increased the OD by 100\% for UNQLp 155 and UNQLp 11. The addition of magnesium and manganese salts together with Tween also significantly increased the OD, reaching similar values to MRS broth. Nonetheless, in all AP supplemented conditions (yeAP and sAP at different $\mathrm{pH}$ ) the time generation increased, reaching exponential phase $24 \mathrm{~h}$ later compared to MRS. At the same time, increasing the $\mathrm{pH}$ of the sAP media from 4.5 (original) to 6.2 shows a considerable increase of the maximum OD. Whereas the reduction of $\mathrm{pH}$ shows a decrease of the maximum OD. Similar results were found when the $\mathrm{pH}$ of MRS was modified.
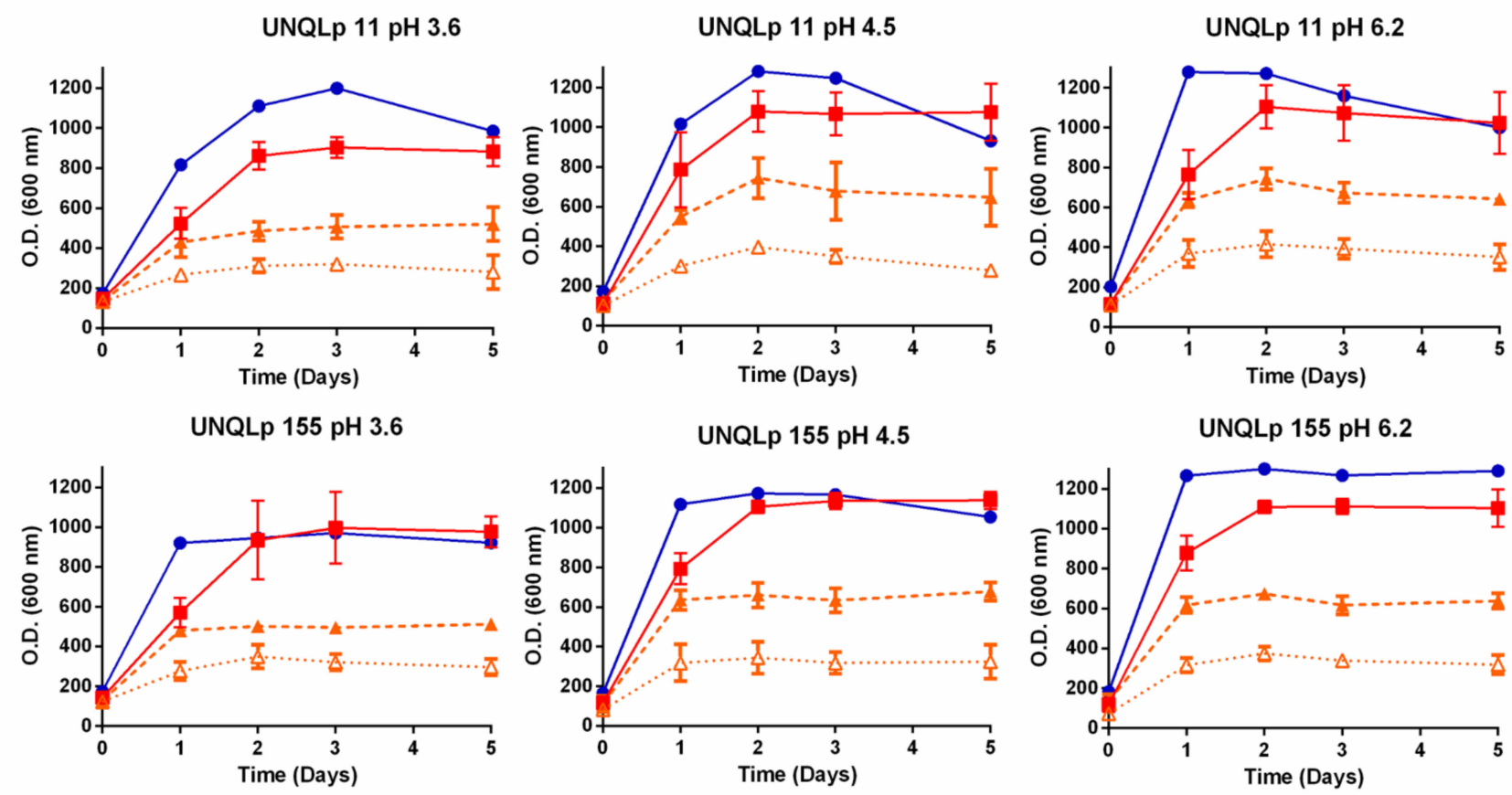

Figure 1. Growth kinetics, by $\mathrm{OD}_{600 \mathrm{~nm}}$ measurement, during incubation of UNQLp 11 and UNQLp 155 strains in $A P(\triangle)$,

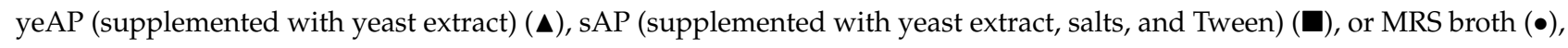
at $\mathrm{pH} 3.6,4.5$ and 6.2 . 
Finally, between pH 3.6 and 6.2, both strains (UNQLp 11 and UNQLp 155) achieved the growth plateau with values of $\sim 9-10 \mathrm{LogCFU} / \mathrm{mL}$ when they were grown in sAP, without significant differences with MRS $(p<0.05)$

\subsection{Behavior of Bacterial Cultures in Synthetic Wine}

Based on the results obtained in Section 3.1, sAP was selected as a growth medium for both Lpb. plantarum strains for the subsequent inoculation in synthetic wine. MRS broth, $\mathrm{pH} 3.8$ and 6.2, was used as control. Bacterial viability, at $24 \mathrm{~h}$ and 7 days, was measured in each sample by plate count (Figure 2). Figure 2 showed a notable decrease in the viability values in synthetic wine after day 7 , compared to $24 \mathrm{~h}$, in all conditions. No significant differences were observed between sAP and MRS broth at different $\mathrm{pH}$. Cultures grown in MRS pH 3.6 were more sensitive to synthetic wine incubation, and the cell survival was significantly lower at $24 \mathrm{~h}$ and 7 days compared to other growth conditions.
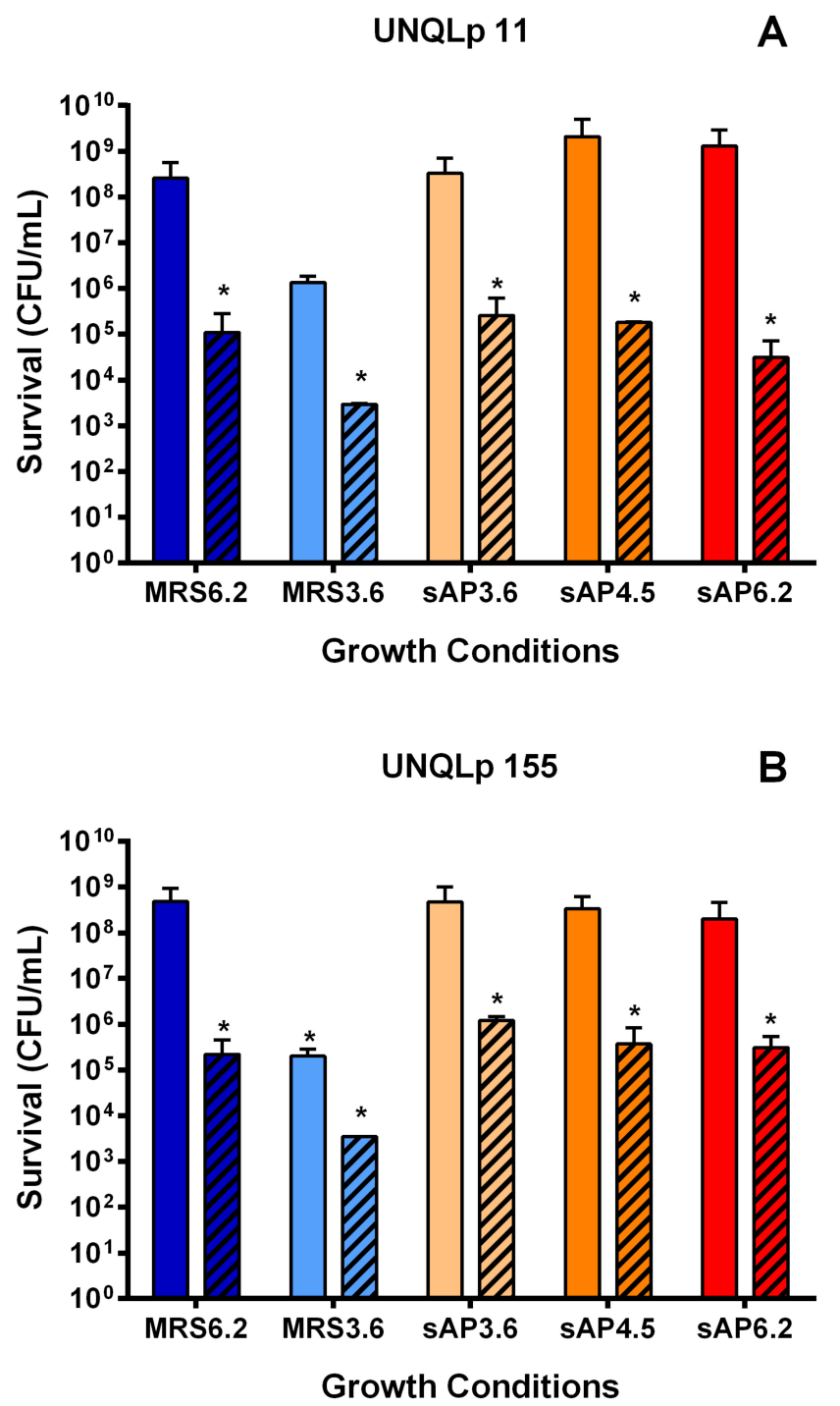

Figure 2. Bacterial viability of UNQLp 11 (A) and UNQLp 155 (B) strains, after $24 \mathrm{~h}$ (smooth bars) and 7 days (striped bars) of incubation in synthetic wine (ethanol 13\% v/v, pH 3.5) at $21^{\circ} \mathrm{C}$. Cultures were grown in sAP (supplemented with yeast extract, salts and Tween), at different $\mathrm{pH}(3.6,4.5$ and 6.2), or in MRS broth (pH 3.6 and 6.2) as control, until stationary phase. The statistical analysis was done using ANOVA and Dunnett's multiple comparisons test with de control (MRS pH 6.2). Differences were considered significant when $p<0.05\left(^{*}\right)$. 
In addition to evaluating viability, L-malic acid consumption was measured after 7 days of incubation in synthetic wine. Figure 3 shows the \%MAC values for UNQLp 11 (Figure 3A) and UNQLp 155 (Figure 3B) strains. The cultures grown in MRS pH 3.6 showed a significant decrease in the \%MAC, in concordance with the cell survival results observed in Figure 2, being the values lower for UNQLp 155 strain. For cultures grown in sAP, no significant differences were observed compared to MRS pH 6.2. Additionally, MRS and $\mathrm{sAP}$ at $\mathrm{pH} 6.2$ showed the highest $\% M A C$ values. For this reason, subsequent experiments were carried out using sAP at $\mathrm{pH} 6.2$, in which both strains were able to consume $\sim 90 \%$ of L-malic acid.

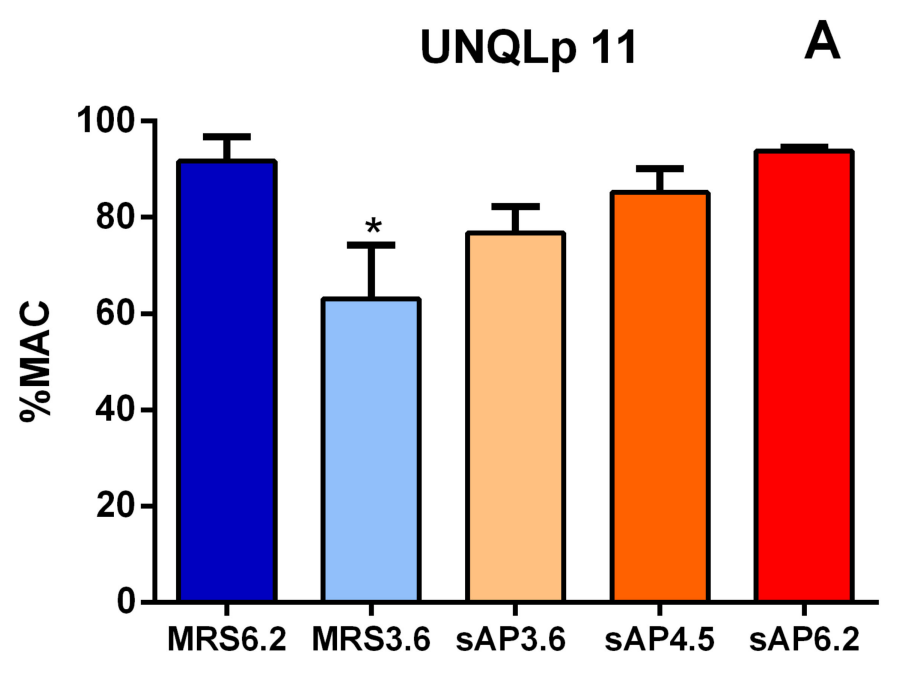

Growth Conditions

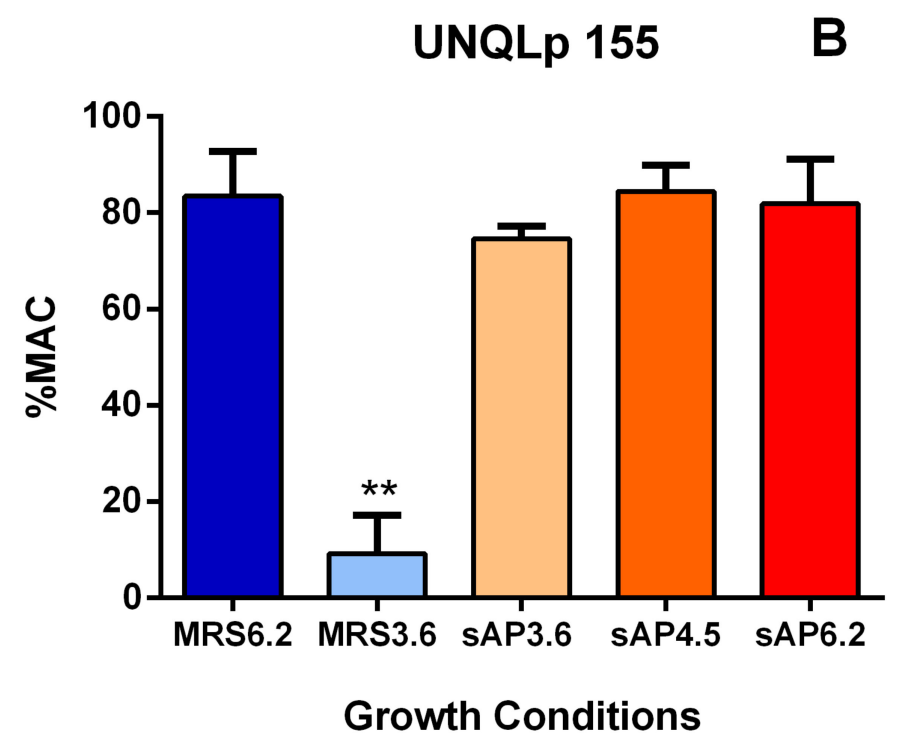

Figure 3. Percentage of L-malic acid consumption (\%MAC) of UNQLp 11 (A) and UNQLp 155 (B) strains, after incubation during 7 days in synthetic wine (ethanol 13\% v/v, pH 3.5), at $21{ }^{\circ} \mathrm{C}$. The statistical analysis was completedusing ANOVA and Dunnett's multiple comparisons test with thecontrol (MRS pH 6.2). Differences were considered significant when $\left.p<0.05{ }^{*}\right)$ or $p<0.01\left(^{* *}\right.$ ).

\subsection{Fermentation Assays in Sterile Wine}

Fermentation assays were carried out on sterile Patagonian Pinot noir and Merlot wine, for 21 days, determining bacterial viability and L-malic acid consumption. As 
described above, cultures from sAP at $\mathrm{pH} 6.2$ were selected for wine inoculation. Two different inoculum sizes $\left(\sim 5.10^{7}\right.$ and $\left.5.10^{8} \mathrm{CFU} / \mathrm{mL}\right)$ were used, as shown in Figures 4 and 5 . Figures 4 and 5 show the fermentation kinetics for UNQLp 11 and UNQLp 155 strains, respectively. In each one, MRS ( $\mathrm{pH}$ 6.2) control was included.

The cell survival of UNQLp 11 and UNQLp 155 strains, in sAP or MRS (Figures 4 and 5), showed a drastic decrease ( $2 \mathrm{log})$ after $24 \mathrm{~h}$ of inoculation, in all conditions. Loss of viability was maintained during fermentation, but to a lesser degree, being more considerable in Merlot wine.

The initial bacterial concentration proved to be crucial for the success of the fermentation assay. At a lower cell concentration, UNQLp 11 strain is able to consume a $20 \%$ of the L-malic acid content during the 21 days of the assay, in both wine varietals, and in cultures from both growth media (Figure 4). When the same strain was inoculated at high bacterial concentration, it showed a \%MAC value higher than $70 \%$ in Merlot wine, and higher than $85 \%$ in Pinot noir wine, without significant differences between cultures grown in MRS broth or sAP media $(p<0.05)$. Similar results were obtained in UNQLp 155 strain (Figure 5). However, when high cell concentrations were inoculated, \%MAC was lower $(\sim 50 \%)$ for cultures grown in sAP media and inoculated in Merlot wine, whereas it was higher than 75\% in Pinot noir (significantly higher than cultures grown in MRS, $p<0.05$ ).

a)

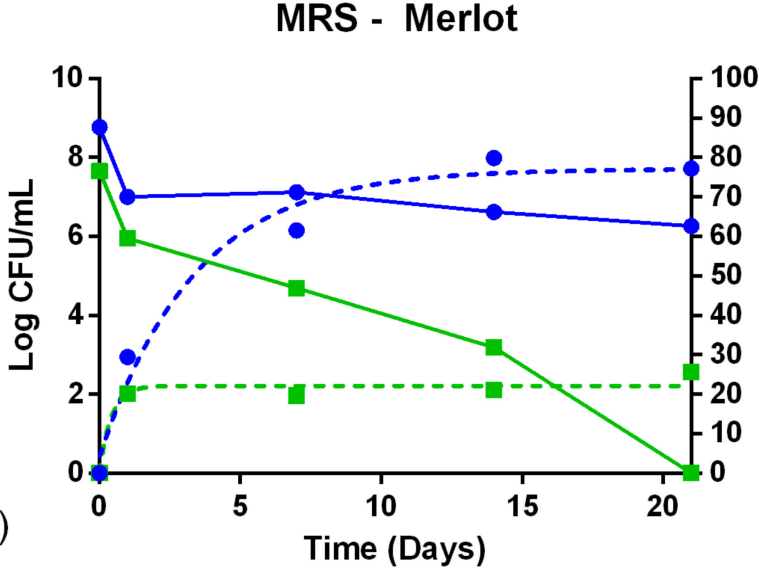

sAP - Merlot

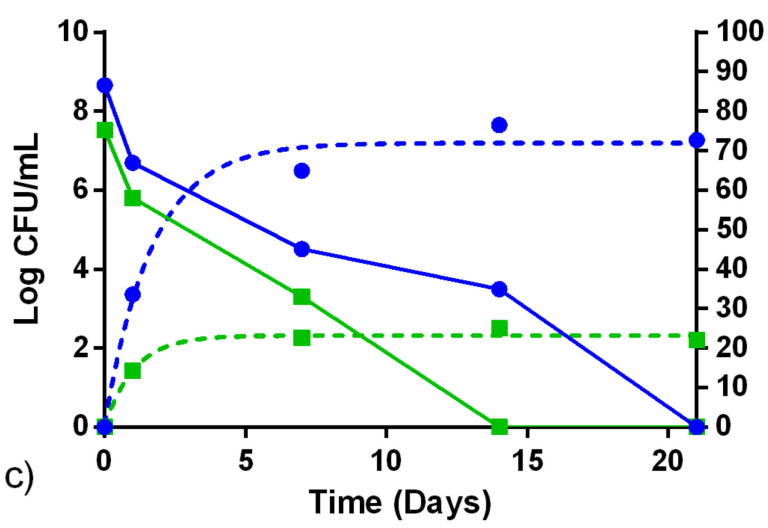

MRS - Pinot noir

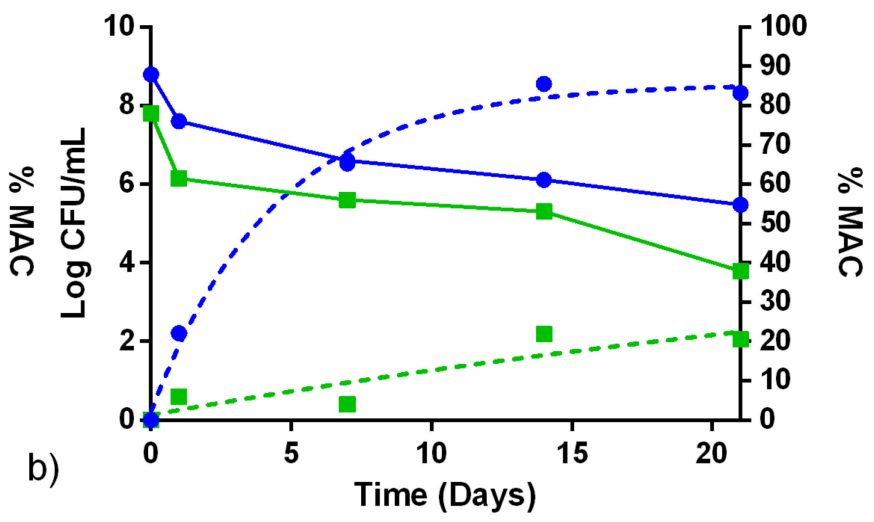

sAP - Pinot noir

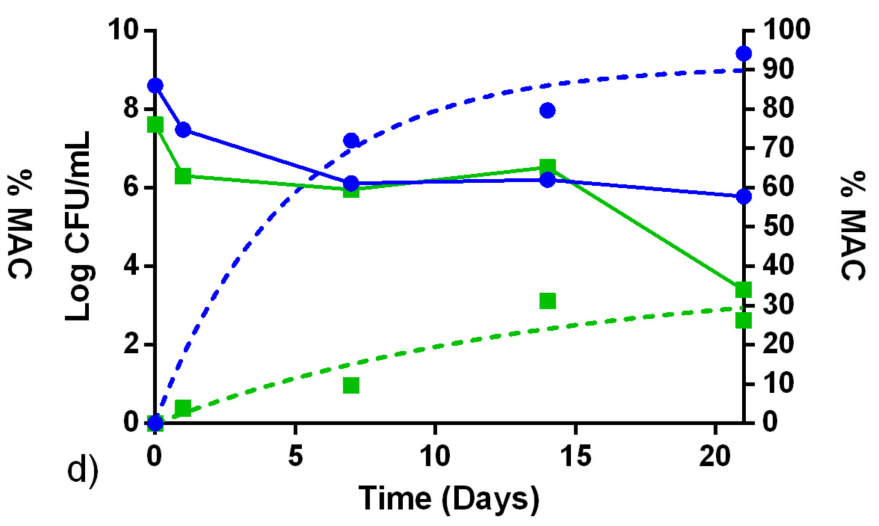

Figure 4. Fermentation assays in sterile Merlot (left column) and Pinot noir (right column) wines, of UNQLp 11 cultures growing in MRS pH $6.2(\mathbf{a}, \mathbf{b})$ or in sAP medium (supplemented with yeast extract, salts, and Tween) pH 6.2 (c,d). The full lines show the count of viables ( $\log \mathrm{CFU} / \mathrm{mL}$ ) and the dotted lines the percentage of L-malic acid consumed (\%MAC), obtained according to a non-linear regression of exponential decay. High size inoculums are displayed in blue and low inoculums in green. 
MRS - Merlot

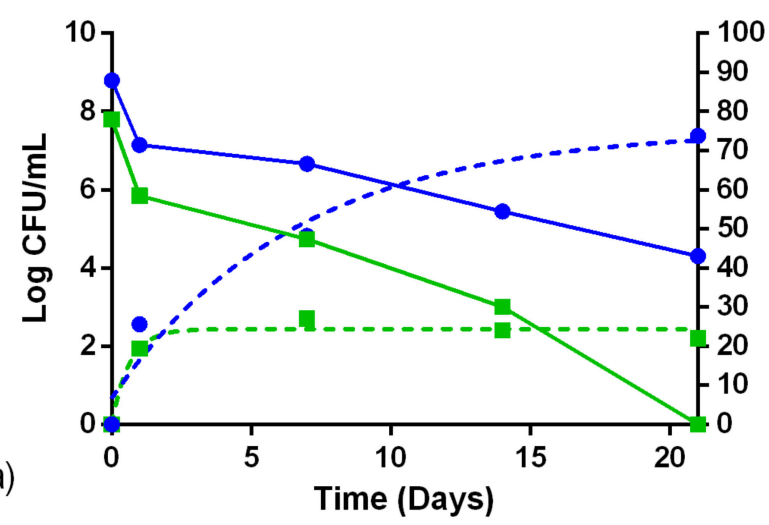

sAP - Merlot

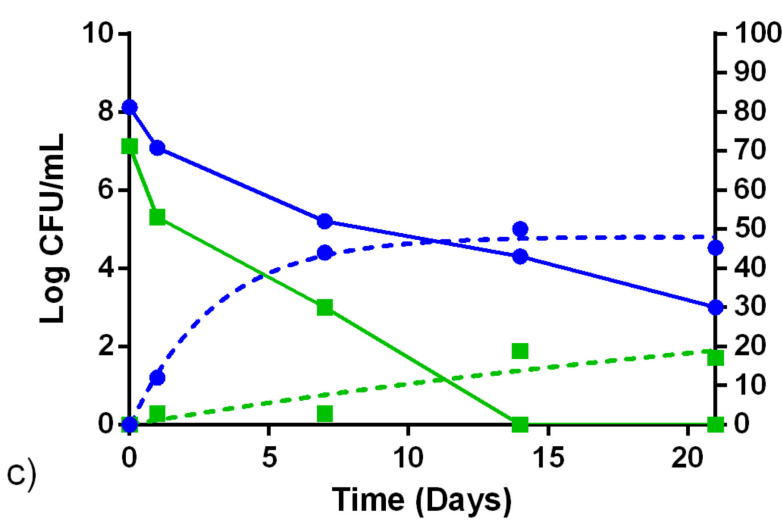

MRS - Pinot noir

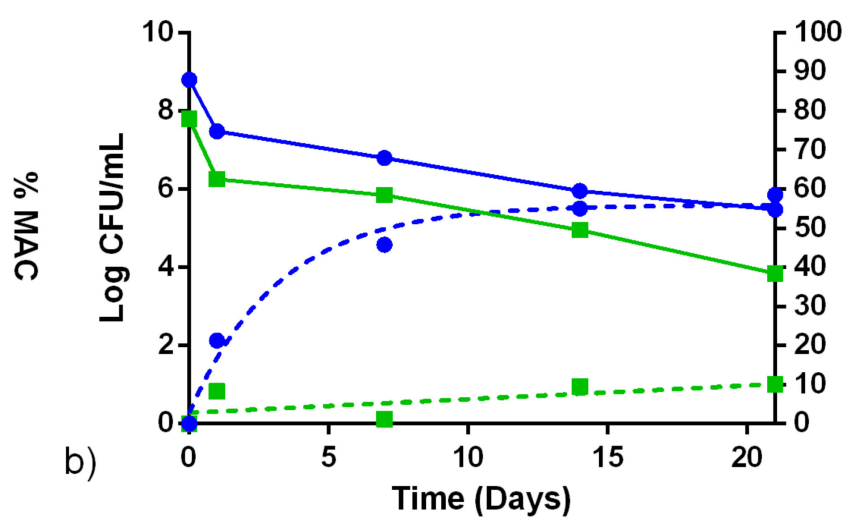

sAP - Pinot noir

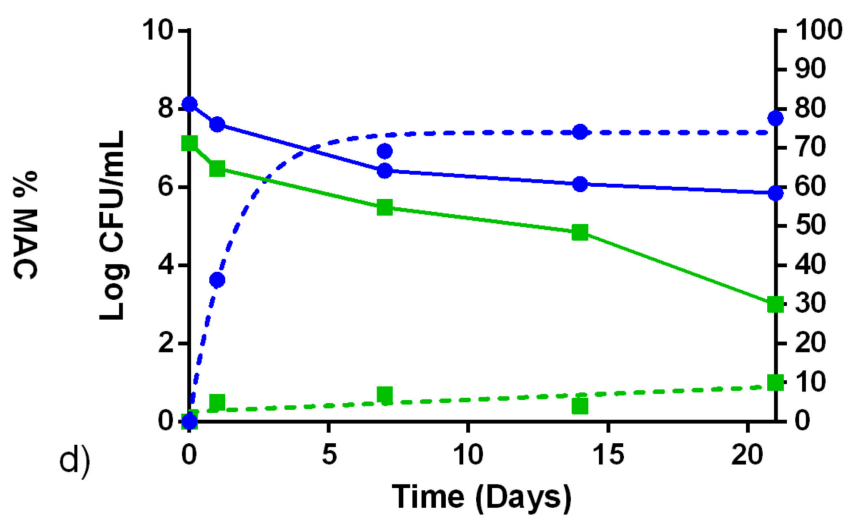

Figure 5. Fermentations in sterile Merlot wines (left column) and Pinot noir (right column) for UNQLp 155 of cultures growing in MRS pH $6.2(\mathbf{a}, \mathbf{b})$ or in sAP medium (supplemented with yeast extract, salts, and Tween) pH 6.2 (c,d). The full lines show the count of viables $(\log \mathrm{CFU} / \mathrm{mL})$ and the dotted lines the percentage of L-malic acid consumed (\%MAC), obtained according to a non-linear regression of exponential decay. High size inoculums are displayed in blue and low inoculums in green.

\section{Discussion}

Previous studies have shown that some Lpb. plantarum strains are able to guide MLF in severe wine conditions (low $\mathrm{pH}$, high ethanol and $\mathrm{SO}_{2}$ ) and have potential to be used as malolactic starter cultures. In addition, they exhibit a more diverse enzymatic profile than O. oeni strains, which could play an important role in the modification of the wine's aromatic profile $[7-9,17,18]$.

The two oenological $L p b$. plantarum strains studied were able to grow similarly in supplemented apple pomace (sAP) media and in MRS broth (control). In previous works [22,23], it was demonstrated that a suitable large biomass of Lpb. plantarum strains could be obtained in a culture medium based on by-products of the food industry (such as whey permeate), with good L-malic acid consumption under wine stress conditions. Since LAB strains are usually grown in the complex medium MRS, this is a very expensive media for bacterial growth at large scale, to be used as starter in industrial food fermentation $[29,30]$. The use of food by-products not only represents a sustainable method for LAB culture, but also reduces drastically the cost of biomass production.

Considering that UNQLp 11 and UNQLp $155 \mathrm{Lpb}$. plantarum strains have potential to be used as native Patagonian starter cultures $[9,17,18,31]$, it is necessary to optimize the obtention of cellular biomass using sources present in the same region. The development of this work allowed formulating an economic culture media based on AP, adding value to a food waste of the apple juice industry. The production of apples is one of the main 
economic activities in the Río Negro province (Patagonian region), being Argentina one of the principal exporters of fresh apples of the South hemisphere, with an annual production of $\sim 1$ million tons [32]. From the total production of apples, $40 \%$ is used by the industry to produce concentrated or pressed juice. From the processed apples, 35\% is apple pomace, which is usually discarded. For these reason, the use of apple pomace would confer an added value and potentially, resolve the environmental impact of its disposal or treatment, reducing their high biochemical oxygen demand [24,25,33].

Although the use of AP to grow oenological LAB has not been reported yet, Berbegal et al. [34] described the use of supplemented apple juice as a base culture medium to grow O. oeni strains. The main carbon sources of AP are glucose, fructose and sucrose, but with low concentration of proteins and other nutrients. This composition makes nutritional supplementation necessary through the incorporation of nitrogen, growth factors, and salts $[26,34]$. According to the results observed in Figure 1, the carbon source present in $\mathrm{AP}$ is adequate, but the supplementation with yeast extract, Tween, manganese, and magnesium are essential for optimal growth. Although supplementation represents an additional cost, they could be replaced by other food waste rich in nutrients, which will be studied in future assays.

In addition, it is important to note that, in this work, cultures inoculated in wine were not acclimated. The increase in cost for the acclimation media is caused by the use of commercial MRS as base medium, as established in Bravo-Ferrada et al., 2014 [21]. Although acclimation treatments showed an increase of the resistance to harsh wine conditions [21], for this work, we focus on finding sustainable, low-cost alternatives for production of starter cultures, thus avoiding the use of acclimation treatments.

Several authors report using LAB inoculums oscillating between 7 to $8 \mathrm{LogCFU} / \mathrm{mL}$, to study fermentation of sterile wine or synthetic wine $[4,6,35,36]$. According to our experience, 7.5 LogCFU/mL is an appropriate inoculum size for strains of O. oeni and $L p b$. plantarum to complete the consumption of L-malic acid in sterile wine in 15-20 days, with a previous acclimation treatment [18]. For this reason, the inoculation with two different inoculums were studied to evaluate the success of MLF. In Figures 4 and 5, a drastic loss of viability occurs after $24 \mathrm{~h}$ of inoculation, and the higher size inoculums perform the best $\% M A C$, consuming more than $75 \%$ of L-malic acid, corresponding to a concentration lower than $0.5 \mathrm{mg} / \mathrm{L}$. This suggests that MLF is complete [9]. The number of viable bacteria throughout the 21 days of fermentation was less than $7 \mathrm{LogCFU} / \mathrm{mL}$, which corresponds to the bacteria that survived and adapted to the stressful factors of the wine, and/or managed to maintain their activity allowing for a more efficient L-malic acid consumption.

Finally, the results of this work represent a valuable alternative for biomass obtention of $L p b$. plantarum as malolactic starter cultures at a low cost and in a sustainable manner. The production of native malolactic starter cultures could improve the quality of regional wines, maintaining the terroir and avoiding the risk of spontaneous MLF. The use of apple pomace as a base medium, adds value to an industry waste by-product from the same region. This can potentially have significant cost advantages with impact in the regional economic activities and satisfy the consumer demand for more environmental-friendly processes.

Author Contributions: Formal analysis, V.C. and E.E.T.; Investigation, V.C., N.S.B., S.M.E.B., B.M.B.F., D.V.L.H. and E.E.T.; Methodology, V.C., N.S.B., S.M.E.B., B.M.B.-F. and D.V.L.H.; Project administration, L.C.S. and E.E.T.; Writing-original draft, E.E.T.; Writing-review and editing, V.C., N.S.B., B.M.B.-F., D.V.L.H., A.C.C., L.C.S. and E.E.T. All authors have read and agreed to the published version of the manuscript.

Funding: This research was funded by grants from Universidad Nacional de Quilmes (Buenos Aires,

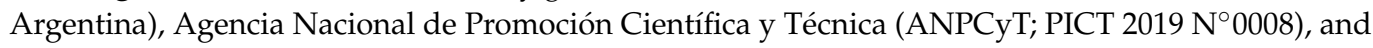
CONICET (PIP-2017-11220170100898C O).

Institutional Review Board Statement: Not applicable.

Informed Consent Statement: Not applicable. 


\section{Data Availability Statement: Not applicable.}

Acknowledgments: L.C.S. and V.L.H.D. are members of the Research Career of the Comisión de InvestigacionesCientíficas de Buenos Aires, Argentina, B.M.B.-F. and E.E.T. are members of the Research Career of the National Scientific and Technical Research Council (CONICET), N.S.B. and S.M.E.B. are post-doctoralfellows of CONICET, and V.C. is a member of Department Biological Sciences, CERMO-FC Research Center, Université du Québec à Montréal (UQAM), Canada.

Conflicts of Interest: The authors declare no conflict of interest.

\section{References}

1. Wibowo, D.; Eschenbruch, R.; Davis, C.R.; Fleet, G.H.; Lee, T. Occurrence and growth of lactic acid bacteria in wine: A review. Am. J. Enol. Vitic. 1985, 36, 302-313.

2. Lonvaud-Funel, A. Lactic acid bacteria in the quality improvement and depreciation of wine. In Lactic Acid Bacteria: Genetics, Metabolism and Applications; Springer: Dordrecht, The Netherlands, 1999; pp. 317-331.

3. Bartowsky, E.J.; Henschke, P.A. Use of a polymerase chain reaction for specific detection of the malolactic fermentation bacterium Oenococcus oeni (formerly Leuconostoc oenos) in grape juice and wine samples. Aust. J. Grape Wine Res. 1999, 5, 39-44. [CrossRef]

4. Pozo-Bayón, M.A.; G-Alegría, E.; Polo, M.C.; Tenorio, C.; Martín-Álvarez, P.J.; Calvo De La Banda, M.T.; Ruiz-Larrea, F.; MorenoArribas, M.V. Wine volatile and amino acid composition after malolactic fermentation: Effect of Oenococcus oeni and Lactobacillus plantarum starter cultures. J. Agric. Food Chem. 2005, 53, 8729-8735. [CrossRef]

5. Valdés La Hens, D.; Bravo-Ferrada, B.M.; Delfederico, L.; Caballero, A.C.; Semorile, L.C. Prevalence of Lactobacillus plantarum and Oenococcus oeni during spontaneous malolactic fermentation in Patagonian red wines revealed by polymerase chain reactiondenaturing gradient gel electrophoresis with two targeted gene. Aust. J. Grape Wine Res. 2015, 21, 49-56. [CrossRef]

6. Lerm, E.; Engelbrecht, L.; du Toit, M. Selection and characterisation of Oenococcus oeni and lactobacillus plantarum South African wine isolates for use as malolactic fermentation starter cultures. S. Afr. J. Enol. Vitic. 2011, 32, 280-295. [CrossRef]

7. Brizuela, N.S.; Bravo-Ferrada, B.M.; Pozo-Bayón, M.Á.; Semorile, L.; Tymczyszyn, E.E. Changes in the volatile profile of Pinot noir wines caused by Patagonian Lactobacillus plantarum and Oenococcus oeni strains. Food Res. Int. 2018, 106, 22-28. [CrossRef]

8. Brizuela, N.S.; Bravo-Ferrada, B.M.; Curilén, Y.; Delfederico, L.; Caballero, A.; Semorile, L.; Pozo-Bayón, M.A.; Tymczyszyn, E.E. Advantages of Using Blend Cultures of Native L. plantarum and O. oeni Strains to Induce Malolactic Fermentation of Patagonian Malbec Wine. Front. Microbiol. 2018, 9, 2109. [CrossRef]

9. Brizuela, N.S.; Franco-Luesma, E.; Bravo-Ferrada, B.M.; Pérez-Jiménez, M.; Semorile, L.; Tymczyszyn, E.E.; Pozo-Bayon, M.A. Influence of Patagonian Lactiplantibacillus plantarum and Oenococcus oeni strains on sensory perception of Pinot Noir wine after malolactic fermentation. Aust. J. Grape Wine Res. 2021, 27, 118-127. [CrossRef]

10. Sumby, K.M.; Bartle, L.; Grbin, P.R.; Jiranek, V. Measures to improve wine malolactic fermentation. Appl. Microbiol. Biotechnol. 2019, 103, 2033-2051. [CrossRef]

11. Lopez, I.; Lòpez, R.; Santamaría, P.; Torres, C.; Ruiz-Larrea, F. Performance of malolactic fermentation by inoculation of selected Lactobacillus plantarum and Oenococcus oeni strains isolated from Rioja red wines. Vitis 2008, 47, 123-129.

12. Du Toit, M.; Engelbrecht, L.; Lerm, E.; Krieger-Weber, S. Lactobacillus: The Next Generation of Malolactic Fermentation Starter Cultures-An Overview. Food Bioprocess Technol. 2011, 4, 876-906. [CrossRef]

13. Garofalo, C.; El Khoury, M.; Lucas, P.; Bely, M.; Russo, P.; Spano, G.; Capozzi, V. Autochthonous starter cultures and indigenous grape variety for regional wine production. J. Appl. Microbiol. 2015, 118, 1395-1408. [CrossRef]

14. Berbegal, C.; Peña, N.; Russo, P.; Grieco, F.; Pardo, I.; Ferrer, S.; Spano, G.; Capozzi, V. Technological properties of Lactobacillus plantarum strains isolated from grape must fermentation. Food Microbiol. 2016, 57, 187-194. [CrossRef]

15. G-Alegría, E.; López, I.; Ruiz, J.I.; Sáenz, J.; Fernández, E.; Zarazaga, M.; Dizy, M.; Torres, C.; Ruiz-Larrea, F. High tolerance of wild Lactobacillus plantarum and Oenococcus oeni strains to lyophilisation and stress environmental conditions of acid $\mathrm{pH}$ and ethanol. FEMS Microbiol. Lett. 2004, 230, 53-61. [CrossRef]

16. Spano, G.; Massa, S. Environmental Stress Response in Wine Lactic Acid Bacteria: Beyond Bacillus subtilis. Crit. Rev. Microbiol. 2006, 32, 77-86. [CrossRef] [PubMed]

17. Bravo-Ferrada, B.M.; Hollmann, A.; Delfederico, L.; Valdés La Hens, D.; Caballero, A.; Semorile, L. Patagonian red wines: Selection of Lactobacillus plantarum isolates as potential starter cultures for malolactic fermentation. World J. Microbiol. Biotechnol. 2013, 29, 1537-1549. [CrossRef]

18. Brizuela, N.S.; Bravo-Ferrada, B.M.; La Hens, D.V.; Hollmann, A.; Delfederico, L.; Caballero, A.; Tymczyszyn, E.E.; Semorile, L. Comparative vinification assays with selected Patagonian strains of Oenococcus oeni and Lactobacillus plantarum. LWT 2017, 77, 348-355. [CrossRef]

19. Brizuela, N.S.; Arnez-Arancibia, M.; Semorile, L.; Pozo-Bayón, M.Á.; Bravo-Ferrada, B.M.; Tymczyszyn, E.E. $\beta$-Glucosidase Activity of Lactiplantibacillus plantarum UNQLp 11 in Different Malolactic Fermentations Conditions: Effect of pH and Ethanol Content. Fermentation 2021, 7, 22. [CrossRef]

20. Cerdeira, V.; Bravo-Ferrada, B.M.; Semorile, L.; Tymczyszyn, E. Design of a low-cost culture medium based in whey permeate for biomass production of enological Lactobacillus plantarum strains. Biotechnol. Prog. 2019, 35, e2791. [CrossRef] [PubMed] 
21. Bravo-Ferrada, B.M.; Tymczyszyn, E.E.; Gómez-Zavaglia, A.; Semorile, L. Effect of acclimation medium on cell viability, membrane integrity and ability to consume malic acid in synthetic wine by oenological Lactobacillus plantarum strains. J. Appl. Microbiol. 2014, 116, 360-367. [CrossRef]

22. Brizuela, N.S.; Arnez-Arancibia, M.; Semorile, L.; Bravo-Ferrada, B.M.; Tymczyszyn, E.E. Whey permeate as a substrate for the production of freeze-dried Lactiplantibacillus plantarum to be used as a malolactic starter culture. World J. Microbiol. Biotechnol. 2021, 37, 115. [CrossRef] [PubMed]

23. Bravo, S.M.E.; Morales, M.; del Mónaco, S.M.; Caballero, A.C. Apple bagasse as a substrate for the propagation of Patagonian wine yeast biomass. J. Appl. Microbiol. 2019, 126, 1414-1425. [CrossRef]

24. Kieliszek, M.; Piwowarek, K.; Kot, A.M.; Pobiega, K. The aspects of microbial biomass use in the utilization of selected waste from the agro-food industry. Open Life Sci. 2020, 15, 787-796. [CrossRef] [PubMed]

25. Lyu, F.; Luiz, S.F.; Azeredo, D.R.P.; Cruz, A.G.; Ajlouni, S.; Ranadheera, C.S. Apple Pomace as a Functional and Healthy Ingredient in Food Products: A Review. Processes 2020, 8, 319. [CrossRef]

26. Santos, M.; Tymczyszyn, E.; Golowczyc, M.; Mobili, P.; Gomez-Zavaglia, A. Probiotic cell cultivation. In Advances in Probiotic Technology; Foerst, P., Santivarangkna, C., Eds.; CRC Press: Boca Raton, FL, USA, 2015.

27. Succi, M.; Pannella, G.; Tremonte, P.; Tipaldi, L.; Coppola, R.; Iorizzo, M.; Lombardi, S.J.; Sorrentino, E. Sub-optimal pH Preadaptation Improves the Survival of Lactobacillus plantarum Strains and the Malic Acid Consumption in Wine-Like Medium. Front. Microbiol. 2017, 0, 470. [CrossRef] [PubMed]

28. De Man, J.C.; Rogosa, M.; Sharpe, M.E. A Medium for the Cultivation of Lactobacilli. J. Appl. Bacteriol. 1960, $23,130-135$. [CrossRef]

29. Hayek, S.A.; Ibrahim, S.A. Current Limitations and Challenges with Lactic Acid Bacteria: A Review. Food Nutr. Sci. 2013, 4, 73-87. [CrossRef]

30. Benaissa, M.; And, H.Z.-K.; Karam, N.-E. Development of a sweet whey-based medium for culture of Lactobacillus. Afr. J. Biotechnol. 2017, 16, 1630-1637. [CrossRef]

31. Brizuela, N.; Tymczyszyn, E.E.; Semorile, L.C.; Valdes La Hens, D.; Delfederico, L.; Hollmann, A.; Bravo-Ferrada, B. Lactobacillus plantarum as a malolactic starter culture in winemaking: A new (old) player? Electron. J. Biotechnol. 2019, 38, 10-18. [CrossRef]

32. Sfara, V.; Fonovich, T.M.; Silvia, C.; Coll, P.; Sfara, V.; Fonovich, T.; Pérez-Coll, C. Sustainable pome fruit production in Patagonia, Argentina. Technol. Acta 2016, 9, 57-61.

33. Champagne, C.P.; Gardner, N.; Doyon, G. Production of Leuconostoc oenos biomass under pH control. Appl. Environ. Microbiol. 1989, 55, 2488-2492. [CrossRef] [PubMed]

34. Berbegal, C.; Benavent-Gil, Y.; Pardo, I.; Ferrer, S. A novel culture medium for Oenococcus oeni malolactic starter production. LWT-Food Sci. Technol. 2015, 64, 25-31. [CrossRef]

35. Maicas, S.; Pardo, I.; Ferrer, S. Continuous malolactic fermentation in red wine using free Oenococcus oeni. World J. Microbiol. Biotechnol. 1999, 15, 737-739. [CrossRef]

36. Thuy, P.T.; Huong, N.L.; Son, C.K. Using Malolactic Fermentation with Acid- and Ethanol-Adapted Oenococcus Oeni Strain to Improve the Quality of Wine from Champs Bourcin Grape in Sapa-Lao Cai. World Acad. Sci. Eng. Technol. 2011, 5, 655-658. 